Original Research Article

\title{
A retrospective study on prevalence of hyperuricemia in patients with hypertension and type 2 diabetes mellitus (T2DM) from a teaching hospital of west Uttar Pradesh, India
}

\author{
Debranjan Datta ${ }^{1}$, Vishal Prakash Giri ${ }^{2 *}$
}

\author{
${ }^{1}$ Department of Pharmacology, \\ Late Shri Lakhiram Agrawal \\ Memorial Government Medical \\ College, Raigarh, Chhattisgarh, \\ India \\ ${ }^{2}$ Department of Pharmacology, \\ SRMS Institute of Medical \\ Sciences, Bareilly, Uttar \\ Pradesh, India \\ Received: 02 November 2018 \\ Revised: 11 December 2018 \\ Accepted: 28 December 2018 \\ *Correspondence to: \\ Dr. Vishal Prakash Giri, \\ Email: drvpgiri@gmail.com \\ Copyright: (C) the author(s), \\ publisher and licensee Medip \\ Academy. This is an open- \\ access article distributed under \\ the terms of the Creative \\ Commons Attribution Non- \\ Commercial License, which \\ permits unrestricted non- \\ commercial use, distribution, \\ and reproduction in any \\ medium, provided the original \\ work is properly cited.
}

\begin{abstract}
Background: Hyperuricemia have been associated with an increased risk for not only type 2 diabetes mellitus (T2DM) and hypertension but also for metabolic syndrome, hyperinsulinemia, gout and many cardiovascular diseases. The objective of the present study was to determine the prevalence of hyperuricemia in patients with hypertension and / or type 2 diabetes mellitus patients from a teaching hospitals of West Uttar Pradesh.

Methods: A retrospective study was carried out in the department of pharmacology, Teerthanker Mahaveer Medical College and Research centre, Moradabad, West Uttar Pradesh over a period of six months.

Results: A total of 524 case records with high blood pressure and / or type 2 diabetes mellitus were examined during the study period. The mean age of subjects reported was 45 years. A $35.3 \%(185 / 524)$ were found to have elevated serum uric acid level. The prevalence of hyperuricemia was found increased with an increased duration of disease among hypertensive, diabetic patients.

Conclusions: A high prevalence of hyperuricemia was observed among patients with hypertension, type 2 diabetes mellitus and among the patients with both comorbidities in our studies.
\end{abstract}

Keywords: Hyperuricemia, Hypertension, Prevalence, Type 2 diabetes mellitus

\section{INTRODUCTION}

According to American College of Rheumatology guidelines, the cut-off uric acid level for hyperuricemia diagnosis varies from $6.1 \mathrm{mg} / \mathrm{dL}$ to $7.0 \mathrm{mg} / \mathrm{dL} .^{1,2}$ More specifically, a serum uric acid level greater than $6.8 \mathrm{mg} / \mathrm{dL}$ at physiological temperature $\left(37^{\circ} \mathrm{C}\right)$ and at neutral $\mathrm{pH}$ is considered as hyperuricemia. ${ }^{3}$ Articular and extra-articular uric acid crystal deposition occurs as a result of high blood urea levels. This often leads to progressive joint destruction, renal failure, and cardiovascular threat., ${ }^{4,5}$ Several study documents that blood uric acid levels below
$6 \mathrm{mg} / \mathrm{dL}$ reduces cardiovascular and renal risks. ${ }^{3,6}$ Several Indian studies reported higher prevalence of hyperuricemia among patients with hypertension $(37.33 \%)$, metabolic syndrome $(47.1 \%)$ and type 2 diabetes mellitus $(25.35 \%)$ in comparison to healthy individuals. ${ }^{7,8}$

In type 2 diabetes mellitus patients, hyperuricemia results due to under excretion of uric acid. This is because of increased renal tubular sodium reabsorption in presence of insulin. Hypertensive patients with concomitant high serum uric acid level reported to be at a greater risk of 
uncontrolled hypertension, despite good compliance with antihypertensive treatment. $^{9}$

The prevalence of hypertension and type 2 diabetes mellitus has increased dramatically globally. Considering the consequences, importance should be given on early screening of serum uric acid levels among hypertensive and diabetic patients for better prevention, and management of complications of type 2 diabetes and hypertension.

\section{METHODS}

Present study was a noninterventional, retrospective study. All the case records with diagnosed type 2 diabetes mellitus alone or hypertension alone or both, for which uric acid level was performed and results were available from medicine OPD of TMU hospital were incorporated in this study.

The study period was all the case records fulfilling inclusion criteria were collected between June and November 2017.

\section{Inclusion criteria}

- $\quad$ Patients with diagnosed type 2 diabetes mellitus.

- Patients who had at least 2 consecutive visits with diagnosis of hypertension or they had prescription of antihypertensive drug with one recording of elevated $\mathrm{BP}$ or they had elevated $\mathrm{BP}$ on two visits. Elevated BP is defined as systolic $\mathrm{BP}>139 \mathrm{mmHg}$ and Diastolic BP (DBP) $>89 \mathrm{mmHg}$ as per JNC 8 .

- For those uric acid findings are available.

\section{Exclusion criteria}

- $\quad$ All type 1 diabetic patients.

- Patients with thyroid disorders, adrenal disorders, proven renovascular hypertension, congestive heart failure.

- Pregnant and breast feeding women.

- Those with regular Smoking habits.

- Alcoholics.

Present study was conducted in accordance with the Declaration of Helsinki, International Conference on Harmonization of Good Clinical Practice guidelines, Indian Council of Medical Research, Indian GCP guidelines and IEC approved protocol.

The data relating to demographic profile of patients (age, gender), duration of type 2 diabetes mellitus and/or hypertension and serum uric acid levels were collected from case records.

Patient's confidentiality was mentioned throughout the study.
Distribution of hyperuricemia among different categories were presented as percentages. Correlation were determined by Chi-Square test.

\section{Statistical analysis}

Data base preparation and analysis was carried out by using IBM SPSS 20.0 statistical software. Descriptive variable were presented as mean \pm standard deviation (SD). Chi Square test $(\mathrm{p}<0.05)$ was considered as statistically significant for associations among different categories.

\section{RESULTS}

A total of 524 case records of either hypertensive and / or type 2 diabetic (T2DM) with available uric acid data were analysed. Out of which $150(28.6 \%)$ subjects were diabetic, $318(60.7 \%)$ were hypertensive and $56(10.7 \%)$ subjects were both diabetic and hypertensive (Table 1). Approximately $35.3 \%$ (185 of 524) of the overall subjects had hyperuricemia. Proportion of hyperuricemia subjects in diabetic, hypertensive and diabetic hypertensive conditions were $32.6 \%, 36.8 \%$ and $33.9 \%$ respectively.

Table 1: Distribution of hyperuricemia among diseases.

\begin{tabular}{|ll|l|}
\hline Variables & N $(\%)$ & $\begin{array}{l}\text { Hyperuricemia } \\
\text { N }(\%)\end{array}$ \\
\hline $\begin{array}{l}\text { Total number } \\
\text { screened }\end{array}$ & 524 & $185(35.3)$ \\
\hline Hypertension & $318(60.7)$ & $117(36.8)$ \\
\hline T2DM & $150(28.6)$ & $49(32.6)$ \\
\hline Diabetic hypertension & $56(10.7)$ & $19(33.9)$ \\
\hline
\end{tabular}

Table 2: Distribution of hyperuricemia by gender.

\begin{tabular}{|lll|}
\hline Gender & $\begin{array}{l}\text { Hyperuricemia } \mathbf{N} \\
(\%)\end{array}$ & P value \\
\hline Male $(\mathrm{N}=354)$ & $124(35)$ & $\mathrm{P}>0.05^{1}$ \\
\hline Female $(\mathrm{N}=170)$ & $61(35.9)$ \\
\hline${ }^{1}$ males vs females, $\mathrm{p}=0.848$, Chi square $=0.0367$
\end{tabular}

Statistically significant association was observed among different age categories (31-40years vs $\leq 30$ years; $p=0.002$ and >40years vs 31-40 years; $p<0.017$ ) with respect to prevalence of HU in subjects with T2DM (Table 2). On the other hand, high prevalence of hyperuricemia was observed by hypertensive subjects aged >40years than those aged $\leq 30$ years $(42.5 \%$ vs $16 \%)$. Association was found statistically significant $(\mathrm{p}=0.012)$.

Hyperuricemia was reported in a higher proportion of females (37.2\% vs $31.4 \%$, for T2DM; $42.8 \%$ VS $32.6 \%$, for diabetic hypertensions) than males except those with hypertension. But comparison was not found statistically significant (Table 3). 
Table 3: Distribution of hyperuricemia among diseases by gender.

\begin{tabular}{|c|c|c|c|}
\hline & $\begin{array}{l}\text { Total no. } \\
(\mathbf{N})\end{array}$ & $\begin{array}{l}\text { Hyperuricemia } \\
\text { N }(\%)\end{array}$ & P value \\
\hline \multicolumn{4}{|c|}{ Hypertension $(\mathrm{N}=318)$} \\
\hline Male & 198 & $75(37.8)$ & \multirow{2}{*}{$\mathrm{P}>0.05^{1}$} \\
\hline Female & 120 & $42(35)$ & \\
\hline \multicolumn{4}{|c|}{ T2DM (N =150) } \\
\hline Male & 107 & $33(31.4)$ & \multirow{2}{*}{$\mathrm{P}>0.05^{2}$} \\
\hline Female & 43 & $16(37.2)$ & \\
\hline \multicolumn{4}{|c|}{ Diabetic hypertension $(\mathrm{N}=56)$} \\
\hline Male & 49 & $16(32.6)$ & \multirow{2}{*}{$\mathrm{P}>0.05^{3}$} \\
\hline Female & 07 & $03(42.8)$ & \\
\hline
\end{tabular}

Table 4: Distribution of hyperuricemia by age group.

\begin{tabular}{|lll|}
\hline Age group (years) & $\begin{array}{l}\text { Hyperuricemia } \mathbf{N} \\
(\%)\end{array}$ & P value \\
\hline$\leq 3(\mathrm{~N}=40)$ & $06(15)$ & $\mathrm{P}>0.05^{1}$ \\
\hline $31-40(\mathrm{~N}=173)$ & $47(27.1)$ & $\mathrm{P}<0.05^{2}$ \\
\hline$>40(\mathrm{~N}=311)$ & $132(42.4)$ & $\mathrm{P}<0.05^{3}$ \\
\hline
\end{tabular}

${ }^{1}$ age category $\leq 30$ years vs. $31-50$ years; $p=0.108$, Chi square $=$ 2.57; ${ }^{2}$ age category $31-40$ years vs $>40$ years, $\mathrm{p}=0.0008$, Chi square $=11.13 ;{ }^{3}$ age category $\leq 30$ years vs $>40$ years, $p=0.0008$, Chi square $=11.18$.

Table 5: Distribution of hyperuricemia among diseases by age group.

\begin{tabular}{|c|c|c|c|}
\hline & $\begin{array}{l}\text { Total } \\
\text { number }\end{array}$ & Hyperuricemia & P value \\
\hline & $(\mathbf{N})$ & $\mathbf{N}(\%)$ & \\
\hline \multicolumn{4}{|c|}{ Hypertension ( $N=318$ ) } \\
\hline$\leq 30$ yrs & 25 & $04(16)$ & $\mathrm{P}>0.05^{1}$ \\
\hline $31-40$ yrs & 105 & $33(31.4)$ & $\mathrm{P}>0.05^{2}$ \\
\hline$>40 \mathrm{yrs}$ & 188 & $80(42.5)$ & $\mathrm{P}<0.05^{3}$ \\
\hline \multicolumn{4}{|c|}{ T2DM (N =150) } \\
\hline$\leq 30$ yrs & 12 & $1(8.3)$ & $\mathrm{P}>0.05^{4}$ \\
\hline $31-40$ yrs & 52 & $10(19.2)$ & $\mathrm{P}<0.05^{5}$ \\
\hline$>40$ yrs & 86 & $38(44.2)$ & $\mathrm{P}<0.05^{6}$ \\
\hline \multicolumn{4}{|c|}{ Diabetic hypertension ( $N=56$ ) } \\
\hline$\leq 30 \mathrm{yrs}$ & 03 & $1(33.3)$ & $\mathrm{P}>0.05^{7}$ \\
\hline $31-40$ yrs & 16 & $4(25)$ & $\mathrm{P}>0.05^{8}$ \\
\hline$>40$ yrs & 37 & $14(38)$ & $\mathrm{P}>0.05^{9}$ \\
\hline
\end{tabular}

${ }^{1}$ age category in hypertension $\leq 30$ years vs. 31-50years; $p=0.124$, Chi square $=2.36 ;{ }^{2}$ age category in hypertension $31-40$ years vs $>$ 40years, $\mathrm{p}=0.06$, Chi square $=3.52 ;{ }^{3}$ age category in hypertension $\leq 30$ years vs $>40$ years, $p=0.012$, Chi square $=6.5$ ${ }^{4}$ age category in T2DM $\leq 30$ years vs. $31-50$ years; $p=0.367$, Chi square $=0.81 ;{ }^{5}$ age category in T2DM 31-40years vs $>40$ years, $p$ $=0.002$, Chi square $=8.89 ;{ }^{6}$ age category in T2DM $\leq 30$ years vs $>$ 40years, $p=0.017$, Chi square $=5.65 ;{ }^{7}$ age category in diabetic hypertension $\leq 30$ years vs. $31-50$ years; $\mathrm{p}=0.76$, Chi square $=$ $0.09 ;{ }^{8}$ age category in diabetic hypertension 31-40years vs $>$ 40years, $p=0.36$, Chi square $=0.82$; ${ }^{9}$ age category in diabetic hypertension $\leq 30$ years vs $>40$ years, $p=0.87$, Chi square $=0.024$
Table 6: Relationship between hyperuricemia and duration of type 2 diabetes and hypertension in diabetics and hypertensive subjects.

\begin{tabular}{|c|c|c|c|}
\hline $\begin{array}{l}\text { Duration } \\
\text { of }\end{array}$ & $\begin{array}{l}\text { Total no. of } \\
\text { subjects }\end{array}$ & $\begin{array}{l}\text { Hyperuricemia } \\
\text { N }(\%)\end{array}$ & P value \\
\hline \multicolumn{4}{|c|}{ Hypertension $(\mathrm{N}=318)$} \\
\hline$<2$ years & 48 & $12(25)$ & \multirow{3}{*}{$\mathrm{P}<0.05^{1}$} \\
\hline 2 - 5years & 142 & $49(35)$ & \\
\hline$>5$ years & 128 & $56(43.8)$ & \\
\hline \multicolumn{4}{|c|}{ T2DM $(N=150)$} \\
\hline$<2$ years & 21 & $6(28.5)$ & \multirow{3}{*}{$\mathrm{P}>0.05^{2}$} \\
\hline 2 - 5years & 76 & 21(39.6) & \\
\hline$>5$ years & 53 & $22(42)$ & \\
\hline
\end{tabular}

${ }^{1}$ duration of hypertension $<2$ years vs $>5$ years, $\mathrm{p}=0.02$, Chi square $=5.17 ;{ }^{2}$ duration of $\mathrm{T} 2 \mathrm{DM}<2$ years vs $>5$ years, $\mathrm{p}=0.30$, Chi square $=1.07$

Among all the subjects recruited, $354(67.5 \%)$ were males and $170(32.4 \%)$ were females (Table 4). The males (35\%) and females (35.9\%) contributed equally for having elevated serum urate levels.

The mean age of study population was 45 years.

Overall (Table 5), a higher proportion of subjects with age $>40$ years reported to have increased serum urate levels as compared to subjects with age $\leq 30$ years $(42.4 \%$ vs $15 \%)$ and $31-40$ years $(42.4 \%$ vs $27.1 \%)$. Hyperuricemia was found more in subjects aged 31-40 years old while compared to those aged $\leq 30$ years $(27.1 \%$ vs $15 \%)$. Similar was observed when subjects with age $>40$ years were compared against $\leq 30$ years $(42.4 \%$ vs $15 \%)$. Both the findings were statistically significant with $\mathrm{p}<0.05$.

A steady increase in prevalence of hyperuricemia (Table 6) was observed with an increase in the duration (from the period of <2years to >5years) of both hypertension $(25 \%$ to $43.8 \% ; \mathrm{P}=0.02)$ and $\mathrm{T} 2 \mathrm{DM}(28.5 \%$ to $42 \%)$.

\section{DISCUSSION}

Diabetes mellitus and high blood pressure are recognised as important risk factors for coronary artery disease, and cerebrovascular diseases globally. The role of hyperuricemia in T2DM is debatable as some researchers report that it to be a resultant effect of diabetes mellitus and others have reported it to be a risk factor for the development of T2DM. Studies has shown that T2DM is a risk factor for nephrolithiasis and has been found to cause urate stones. ${ }^{10}$ Various other studies also reported that hyperuricemia may be an independent risk factor for $\mathrm{T} 2 \mathrm{DM}$ and hypertension and by lowering the serum urate levels, the risk of these disease can be lowered.

It is estimated that by 2025 , there will be upsurge of incidences of diabetes and to 300 million and 1.56 billion globally, respectively. ${ }^{11}$ 
Our retrospective study reported the overall prevalence rate of hyperuricemia of $35.3 \%$. It was found somewhat similar in both the sexes with female in slightly upper side $(35.9 \%$ vs $35 \%)$. Similar prevalence of hyperuricemia was documented in various studies from different population. ${ }^{12,13}$ Whereas, various other studies have reported higher serum uric acid levels in males than females. ${ }^{14,15}$ This may be due to the fact that presence of estrogen in premenopausal females, enhances renal urate clearance by inhibition of renal urate reabsorption, resulting in low serum urate levels.

The share of hypertensive subjects with hyperuricemia (36.8\%) was found higher than diabetic as well as diabetic hypertensive subjects in present study. Lower proportion of diabetics (32.6) with elevated serum uric acid was observed similar to previous published literature where around $25 \%$ of T2DM patients were reported to have elevated levels of serum uric acid. ${ }^{14}$ This variation may be due to topographical, genetic and lifestyle variations.

In present study serum urate levels were reported to increase with advancing age. This was supported by several other studies. ${ }^{16,17}$ Maximum subjects with hyperuricemia were evident in the age category of $>40$ years followed by 31-50years and $\leq 30$ years. Similar results were reported in hypertensive as well as T2DM subjects. This finding was found statistically significant in our settings. There were no significant age categorical differences in diabetic hypertensive subjects, which differs from study findings of Billa et al. ${ }^{17}$

In present study, a trend in increased prevalence of hyperuricemia was reported with an increase in the duration of disease like T2DM and hypertension. Major limitation of our study is that, as it was a retrospective study, no healthy control group was available to compare the serum urate levels between patients of different comorbidities and healthy volunteers.

\section{CONCLUSION}

The overall prevalence rate of hyperuricemia in our study was $35.3 \%$. Hyperuricemia was observed more among hypertensives $(36.8 \%)$, of ages $>40 y e a r s$. No significant difference was observed between genders. There was an increasing trend in the prevalence of $\mathrm{HU}$ with age and progressing years of duration of T2DM and HTN. Increase in prevalence of hyperuricemia was reported with increased duration of disease.

Funding: No funding sources Conflict of interest: None declared

Ethical approval: The study was approved by the Institutional Ethics Committee

\section{REFERENCES}

1. Hamburger M, Baraf HS, Adamson TC, Basile J, Bass L, Cole B, Doghramji PP, Guadagnoli GA, Hamburger
F, Harford R, Lieberman III JA. 2011 recommendations for the diagnosis and management of gout and hyperuricemia. Postgrad Med. 2011 Nov 2;123(sup1):3-6.

2. Khanna D, Fitzgerald JD, Khanna PP, Bae S, Singh MK, Neogi T, et al 2012 American College of Rheumatology guidelines for management of gout. Part 1: systematic nonpharmacologic and pharmacologic therapeutic approaches to hyperuricemia. Arthritis Care Res. 2012 Oct 1;64(10):1431-46.

3. Richette P, Bardin T. Gout. Lancet. 2010;375(9711):318-28.

4. Juraschek SP, Kovell LC, Miller ER, Gelber AC. Association of kidney disease with prevalent gout in the United States in 1988-1994 and 2007-2010. Semin Arthritis Rheum. 2013;42(6):55161.

5. Clarson LE, Hider SL, Belcher J, Heneghan C, Roddy E, Mallen CD. Increased risk of vascular disease associated with gout: a retrospective, matched cohort study in the UK Clinical Practice Research Datalink. Ann Rheumatic Dis. 2015 Apr 1;74(4):642-7.

6. Choi HK, Mount DB, Reginato AM. Pathogenesis of gout. Ann Internal Med. 2005 Oct 4;143(7):499-516.

7. Billa G, Dargad R, Mehta A. Prevalence of Hyperuricemia in Indian Subjects attending Hyperuricemia Screening Programs-A Retrospective Study. J Assoc Physicians India. 2018 Apr;66:43.

8. Remedios C, Shah M, Bhasker AG, Lakdawala M. Hyperuricemia: a reality in the Indian obese. Obesity Surgery. 2012 Jun 1;22(6):945-8.

9. Yamanaka H. Japanese guideline for the management of hyperuricemia and gout. Nucleosides Nucleotides Nucleic Acids. 2011 Dec 1;30(12):1018-29.

10. Cameron MA, Maalouf NM, Adams-Huet B, Moe OW, Sakhaee K. Urine composition in type 2 diabetes: predisposition to uric acid nephrolithiasis. J Am Soc Nephrol. 2006 May 1;17(5):1422-8.

11. King H, Aubert RE, Herman WH. Global burden of diabetes, 1995-2025: prevalence, numerical estimates, and projections. Diabetes Care. 1998 Sep 1;21(9):1414-31.

12. Ogbera AO, Azenabor AO. Hyperuricaemia and the metabolic syndrome in type 2 DM. Diabetol Metabolic Syndrome. 2010 Dec;2(1):24.

13. Tuomilehto J, Zimmet P, Wolf E, Taylor R, Ram P, King H. Plasma uric acid level and its association with diabetes mellitus and some biologic parameters in a biracial population of Fiji. Am J Epidemiol. 1988 Feb 1;127(2):321-36.

14. Mundhe SA, Mhasde DR. The study of prevalence of hyperuricemia and metabolic syndrome in type 2 diabetes mellitus. Int J Adv Med. 2016;3:241-9.

15. Remedios C, Shah M, Bhasker AG, Lakdawala M. Hyperuricemia: a reality in the Indian obese. Obesity Surg. 2012 Jun 1;22(6):945-8.

16. Culleton BF, Larson MG, Kannel WB, Levy D. Serum uric acid and risk for cardiovascular disease and death: the Framingham Heart Study. Ann Internal Med. 1999 Jul 6;131(1):7-13. 
17. Billa G, Dargad R, Mehta A. Prevalence of Hyperuricemia in Indian Subjects attending Hyperuricemia Screening Programs-A Retrospective Study. J Assoc Physicians India. 2018 Apr;66:43.
Cite this article as: Datta D, Giri VP A retrospective study on prevalence of hyperuricemia in patients with hypertension and type 2 diabetes mellitus from a teaching hospital of west Uttar Pradesh, India. Int J Basic Clin Pharmacol 2019;8:206-10. 